\title{
EFFECT OF NURSE-LED HEALTH EDUCATION ON POST TRAUMATIC STRESS SYMPTOMS AMONG INTERNALLY DISPLACED PERSONS IN JOS, NORTHERN NIGERIA
}

\author{
${ }^{1}$ Ajio, D. Kwambe \\ ${ }^{I}$ Department of Nursing Sciences, Faculty of Health Sciences and Technology University of Jos, \\ Nigeria \\ ${ }^{2}$ Ehiemere, O. Ijeoma \\ ${ }^{2}$ Department of Nursing Sciences, Faculty of Health Sciences and Technology, \\ University of Nigeria Enugu Campus, Nigeria \\ ${ }^{3}$ Iheanacho, N. Peace \\ ${ }^{3}$ Department of Nursing Sciences, Faculty of Health Sciences and Technology, \\ University of Nigeria Enugu Campus, Nigeria
}

Article DOI: https://doi.org/10.36713/epra5340

\begin{abstract}
Introduction: Internal displacement occurred due to armed conflict or other forms of disasters; it was associated with the development of Post-Traumatic Stress (PTS) symptoms. The available interventions for PTS might be costly or not affordable for people in distress in low resource settings; hence, the need to explore alternative options. This study investigates the effect of a nurse-led health education intervention package on PTS symptoms among Internally Displaced Persons (IDPs). We hypothesised that "there is no statistically significant difference in PTS symptoms scores among IDPs before and after intervention with nurse-led health education.

Methods: A quasi-experimental design was employed for the study. Post-Traumatic Stress short-form scale (PTS-8) was used as an instrument for data collection. Data were analysed using SPSS version 23. The socio-demographics are presented in simple percentages and tables. Unpaired student t-test was used to determine the significant differences among variables of interest in the hypothesis generated.

Results: Most common PTS symptoms identified among the IDPs included recurrent memories with means and standard deviations (M 2.92, S.D 0.778); nightmare/sleep disturbance (M 2.26, SD 0.853) and feeling jumpy, easily startled and fearful (M 2.20, SD 0.969). Nurse-led health education caused a reduction in PTS symptoms severity. There was a significant difference in the PTS symptom scores before $(2.3 \pm 1.7)$ and after $(1.7 \pm 0.7)$ the intervention with a score of $2.37, \mathrm{p}=0.020$.

Conclusion: The nurse-led health education practised in undeveloped nature modified environment reduced PTS symptoms severity among the IDPs. It should be used as a tool for reducing the symptoms of PTS among IDPs, especially in contexts that are deficient in already developed recreational and traumatic stress healing facilities.
\end{abstract}

KEYWORDS: Posttraumatic stress, Nurse-led health education, internally displaced persons. 


\section{SJIF Impact Factor: 7.001| ISI I.F.Value:1.241| Journal DOI: 10.36713/epra2016 ISSN: 2455-7838(Online) EPRA International Journal of Research and Development (IJRD)}

\section{BACKGROUND}

Internally Displaced Persons (IDPs) are compelled to escape their home yet stay inside their nation's jurisdiction (Mooney, 2005). They are frequently alluded to as evacuees, even though they don't fall inside refugees' legitimate meanings (Owoaje et al., 2016). As reported by the United Nations High Commissioner for Refugees, there was an increasing number of IDPs globally secondary to armed conflict with an estimated 65.6 (Morina et al., 2018). Displaced persons were commonly found in Ethiopia, Syria, Afghanistan, Democratic Republic of Congo, and Burkina Faso (Internal Displacement Monitoring Centre, 2020). Africans were the predominant population (Owoaje et al., 2016). Mental health problems were among their numerous problems (Haagen et al., 2017).

Posttraumatic stress (PTS) resulting from exposure to a traumatic event(s) such as war, terrorist attack, rape, hurricanes, fatal accidents, and flood are increasingly becoming public health concern globally (Roberts et al., 2019). These everyday traumatic experiences are evident in contemporary times and are categorised as either, human-made or natural disasters (Brooks et al., 2019; Lewis et al., 2019). Human-made and natural disasters such as armed conflicts, chemical spills, air and road accidents are well known to have resulted in much destruction and displacement (Klaus \& Pachocka, 2019; Marshall et al., 2020; Zhang \& Zhang, 2019). Over the past ten years, there has been a significant shift in the attention given to traumatic events on individuals, families, and communities (Hu et al., 2019; Satkoske et al., 2019). Traumatic stress, and posttraumatic stress mainly, have gained International prominence as conditions that affect people across the globe in the wake of exposure to extreme life events, be these collective or individual and therefore calls for attention from all and sundry to help decrease it (Sepahvand et al., 2019; Spialek et al., 2019). In recent years, Nigeria had experienced series of disasters and catastrophes which are mostly humanmade such as insurgency, terrorist attacks, and civil strife including religious and communal conflicts (Ede, 2019; Olanrewaju et al., 2019). Other natural calamities like flood, desert encroachment and landslides have led to an increase in the number of Internally Displaced Persons (IDPs) in the Northern part of Nigeria, including Plateau State (Michael Ihuoma, 2019; Olanrewaju et al., 2020). The prevalence of PTS among IDPs in the community was $46.1 \%$ in Plateau state (Ellis et al., 2019; Tagurum et al., 2014). Severe exposure to violence can produce PTS (Ellis et al., 2019; Fingerle \& Wink, 2020). Other studies have also shown a significant relationship between exposure to violence and the development of PTS comorbidities (Muir et al., 2019; Siriwardhana et al., 2019). In Africa, there is a high prevalence of PTS and lack of suitable intervention that is cost-effective, unlike what is found in the developed nations.

PTS symptoms were managed using the drug (pharmacological), and non-drug (nonpharmacological) approaches (de Moraes Costa et al., 2020; Mavranezouli et al., 2020). The nonpharmacological approaches such as Eye movement desensitisation and reprocessing (EMDR), Cognitive behavioural therapy (CBT) and group therapy were found to be effective (Bisson et al., 2020). However, these interventions might be challenging to implement among IDPs in Africa due to lack of purchasing power for drugs, the need for local adaptation of the interventions, and a trained specialist. Psycho-education might promote individuals coping with mental health problems. Review evidence has shown that it was useful for stress reduction $(\mathrm{d}=0.27)$ (Van Daele et al., 2012). Hence, the need to utilise locally developed content using the resources that might be culturally acceptable. Therefore, this study was designed to assess the effect of a nurse-led health education linkage on posttraumatic stress symptoms among internally displaced persons. We hypothesised no statistically significant difference in PTS symptoms scores among the study population before and after intervention with nurse-led health education.

\section{METHODS}

A quasi-experimental design was employed in this study. A single group pre-test/post-test design was used (Polit et al., 2006). To examine the need for enlightenment on PTS and empowerment with coping strategies among the IDPs, a Focus Group Discussion (FGD) was conducted among four (4) individuals (IDPs). The information generated via a questionnaire (PTS-8) and the FGD before intervention (pre-test) guided the preparation of the nurse-led health education intervention package delivered through 7 sessions of 50 minutes each.

The contents of the Intervention package included coping skills and strategies like breathing retraining, drop-three (jaw, shoulders and the stomach), grounding and safe place exercises using lecture-discussion and demonstration methods of teaching and learning. Alongside the FGDs, baseline data were obtained from the recruited participants. Ethical clearance was obtained from Plateau state Specialist Hospital, Jos, Plateau state, and House of Recab.

\section{PARTICIPANTS}

The IDPs, made up of men and women, were displaced due to ethnoreligious conflicts from the affected local government areas like Jos south and North, Riyom, Shendam. Some came from neighbouring states like Bauchi, and the most 


\section{SJIF Impact Factor: 7.001| ISI I.F.Value:1.241| Journal DOI: 10.36713/epra2016

enduring and prevalent ones are from Gwoza area of Borno State of Nigeria displaced by the Boko Haram insurgency. Most of these people are farmers, while few are traders and civil servants. Almost all of them understand and can speak the "Hausa" language. Plateau state had approximately 250,000 registered IDPs in camps (Adamu \& Rasheed, 2016). However, most of these IDPs still left the camps and got integrated into various communities. Subjects are considered eligible for inclusion in this study if: (1) they are male or female IDPs, (2) $\geq 15$ years, (3) residing in the House of Recab IDPs camp without a history of mental illness before exposure to violence, or traumatic events. Those excluded from participation were those (1) whose ages were below 15 years, and (2) those who refused to participate in the study, and of course, (3) those who had notable mental health challenges before the current traumatic incidents under consideration.

The displaced persons lived in camps and their families (Uzobo et al., 2018). They were supported by government and non-governmental organisations for aids in security, shelter, foods, healthcare, water, and education (Uzobo et al., 2018). The study setting is the House of Recab IDPs Camp in Jos, Plateau State of Nigeria

A total of 50 subjects residing in House of Recab were recruited. We employed the convenience sampling technique in recruiting male and female subjects 15 years and above, without the history of mental health challenges before traumatic events that led to their internal displacement who consented voluntarily to participate in the study.

\section{Interventions}

Nurse-led health education package is a seven-session package; each lasting for 50 minutes of instructional interactions and 60 minutes of practical exercises. The first session of the package is on common reactions to trauma, PTS and its symptoms, the second deals with coping skill of breathing retraining to reduce tension, third are on drop-three, fourth on grounding, while the fifth deals with two words best-self statements and orderly use of tools, i.e., breathing, calming phrases, and best-self statements. Sessions six and seven are on assertion, acceptance and serenity prayers. It is practised in undeveloped nature modified environments or settings, hence developed stress relieving, recreational facilities are lacking in Jos, and alternative strategies need to be explored. The lecture-discussion, demonstrations, and review of assignments were held on Saturdays. even weeks.

Four (4) nurse research assistants who consented to participate in the study were recruited conveniently without blinding from the Plateau Specialist Hospital Jos. They were recruited and trained for five days for sound orientation for effectiveness in interaction interviewing. Four (4) weeks were used in all, for data collection. Through the camp leadership, formal access was gained to the IDPs who consented to participate in the study and, signed an informed consent form. Baseline data were collected before the intervention. The FGD was made up of 4 discussants. The discussions were held in a safe and quiet place in Jos city, conducted by the principal investigator and four nurses using a questionnaire guide to direct the conversations. One nurse took notes, another audio-recorded the discussions, which were edited and transcribed by two nurses immediately after the sessions. The intervention was then administered on the participants for seven (7) weeks after which post-test (T2) data were collected after two weeks postintervention.

\section{The specific objectives of the study are to: \\ 1. Describe demographic characteristics of participants (IDPs).}

2. Identify the most common PTS symptoms experienced by the study IDPs.

3. Determine the nurse-led health education intervention package's effect on the IDPs' most common PTS symptoms.

\section{Procedure and instruments for data collection}

The demographic data (i.e., gender, age, marital status, levels of education, and occupation) and clinical data (i.e., PTS symptoms) were collected at baseline and post-intervention by trained research assistants.

Hausa version of the PTS-8 was used for data collection. It is an adapted instrument from Standardised Post Traumatic Stress Short-formedscale derived from Harvard Trauma Questionnaire (HTQ) designed by Harvard programme in refugee trauma at Massachusettes General Hospital for symptomatic posttraumatic stress with four intrusive items (B1, B2, B3, and B4 and B5 combined), two avoidance items ( $\mathrm{C} 1$ and $\mathrm{C} 2$ ) and two hypervigilance items (D4 and D5) and answered on 4 points Like t- type scale with the cut - off means of 2.20 as against 3.50 since the focus is not on the diagnosis of the disorder but symptomatic posttraumatic stress (Hansen et al., 2010). PTS-8 was psychometrically tested, and it shows a two-four factor solution with one of the models having a dysphoria factor correlated with anxiety and depression (Hansen et al., 2010). Most importantly, the instrument appears to have good psychometric properties on victims of disaster, rape and whiplash patients (Hansen et al., 2010). Its test-retest reliability co-efficient was satisfactory (Hansen et al., 2010). 


\section{EPRA International Journal of Research and Development (IJRD) \\ Volume: 6 | Issue: 1 | January 2021 \\ - Peer Reviewed Journal}

The instrument was translated into Hausa following the international recommendations, and was found to be reliable with Cronbach alpha of 0.83 , the level of significant was put at $<0.05$.

\section{METHODS OF DATA ANALYSIS}

Data were analysed using the Statistical Package for the Social Sciences (SPSS version 23).Data obtained were analysed quantitatively and qualitatively, and presented in percentages, narrative form and tables, using inferential statistics. Unpaired
Student's t-test was used for the analysis of the hypothesis generated. FGD analysis was thematically done with central themes and sub-themes. Major themes included Internal displacement, Traumatic events, Experiences and Daily activities affected. Sub-themes included Knowledge deficit about PTS and Coping skills, demand for empowerment with coping strategies for utilisation. This enhanced motivation for the study and focused on the content of the Nurse-led health education package.

\section{RESULTS}

Objective One (1): Social-demographic characteristics of participants

Table: 1: Socio-Demographic Description of Participants

\begin{tabular}{|c|c|c|c|}
\hline $\mathbf{S} / \mathbf{N}$ & Items & Frequency(f) & Percentage (\%) \\
\hline \multirow[t]{8}{*}{1.} & Age & & \\
\hline & $15-20$ years & 31 & 62.0 \\
\hline & $21-25$ years & 7 & 14.0 \\
\hline & $26-30$ years & 5 & 10.0 \\
\hline & $31-35$ years & 2 & 4.0 \\
\hline & $36-40$ years & 1 & 2.0 \\
\hline & 41 and above years & 4 & 8.0 \\
\hline & Total & 50 & 100 \\
\hline \multirow[t]{4}{*}{2.} & Gender & & \\
\hline & Male & 24 & 48.0 \\
\hline & Female & 26 & 52.0 \\
\hline & Total & 50 & 100 \\
\hline \multirow[t]{6}{*}{3.} & Marital Status & & \\
\hline & Married & 20 & 40 \\
\hline & Single & 30 & 60 \\
\hline & Divorced & -- & -- \\
\hline & Widowed & -- & -- \\
\hline & Total & 50 & 100 \\
\hline \multirow[t]{6}{*}{4.} & Educational Level & & \\
\hline & Non formal education & 11 & 22 \\
\hline & Primary education & 11 & 22.0 \\
\hline & Secondary education & 1 & 58 \\
\hline & Tertiary education & 50 & 2.0 \\
\hline & Total & & 100 \\
\hline \multirow[t]{8}{*}{5.} & Occupation & & \\
\hline & Civil servant & 2 & 4 \\
\hline & Trading & 2 & 4.0 \\
\hline & Artisan & 1 & 2 \\
\hline & Unemployed & 5 & 10.0 \\
\hline & Farming & 25 & 70.0 \\
\hline & Others & 5 & 10.0 \\
\hline & Total & 50 & 100 \\
\hline
\end{tabular}

Table 1 above describes the sociodemographic characteristics of the respondents. A total of 50 internally displaced persons (IDPs) participated in this study. The age distribution of the respondents reveals that $31(62.0 \%)$ of the respondents were between the ages of 15-20 years, $7(14.0 \%)$ were between the ages of $21-25$ years,
$5(10.0 \%)$ were between the ages of 26-30 years, $2(4.0 \%)$ were between the ages of $31-35$ years, $1(2.0 \%)$.

Objective two: Identify the most common PTS symptoms experienced by the study IDPs.

As shown in Table 2, the experiences of the IDPs in mean scores are idehtified. The most 


\section{EPRA International Journal of Research and Development (IJRD) \\ Volume: 6 | Issue: 1 | January 2021 \\ - Peer Reviewed Journal}

common and severe symptoms among the IDPs are the recurrent thought or memory $(62 \%)$ which led to weakness, sadness and loss of appetite, followed by Recurrent nightmare/dream (56.5\%) about the events leading to fear and sleep disturbance at night. After these, the third symptom is easily startled, feeling jumpy and fearful with various mean scores of 2.92, 2,26 and 2.20 , respectively.

Table 2: PTS symptoms experienced by the IDPs ( $\mathrm{N}=50)$

\begin{tabular}{|c|c|c|c|c|c|c|c|c|c|c|c|}
\hline \multirow[t]{2}{*}{ S/N } & \multirow[t]{2}{*}{ Items } & \multicolumn{2}{|c|}{$\begin{array}{c}\text { Not at all } \\
1 \\
\end{array}$} & \multicolumn{2}{|c|}{$\begin{array}{c}\text { Rarely } \\
2\end{array}$} & \multicolumn{2}{|c|}{$\begin{array}{c}\text { Sometimes } \\
3\end{array}$} & \multicolumn{2}{|c|}{$\begin{array}{c}\text { Most of the time } \\
4\end{array}$} & \multirow[t]{2}{*}{ Mean } & \multirow[t]{2}{*}{$\begin{array}{l}\text { Standard } \\
\text { deviation }\end{array}$} \\
\hline & & $\mathbf{F}$ & P\% & $\mathbf{F}$ & P\% & $\mathbf{F}$ & P\% & $\mathbf{F}$ & $\mathrm{P} \%$ & & \\
\hline 1. & $\begin{array}{c}\text { Recurrent thoughts or } \\
\text { memories of the event(s) } \\
\text { which results in weakness, } \\
\text { loss of appetite and sadness. }\end{array}$ & 2 & 4.0 & 11 & 22.0 & 26 & 52.0 & 11 & 22.0 & 2.92 & 0.778 \\
\hline 2. & $\begin{array}{l}\text { Feeling as though the event } \\
\text { is happening again, } \\
\text { culminating in fear. }\end{array}$ & 10 & 20.0 & 24 & 48.0 & 14 & 28.0 & 2 & 4.0 & 2.16 & 0.792 \\
\hline 3. & $\begin{array}{c}\text { Recurrent } \\
\text { nightmares/dreams about } \\
\text { the event(s) making me } \\
\text { afraid of the night or the } \\
\text { sleep. }\end{array}$ & 11 & 22.0 & 17 & 34.0 & 20 & 40.0 & 2 & 4.0 & 2.26 & 0.853 \\
\hline 4. & $\begin{array}{l}\text { Sudden emotional or } \\
\text { physical reactions when } \\
\text { reminded of the events, e.g. } \\
\text { sweating, loss of appetite, } \\
\text { headache and running } \\
\text { stomach. }\end{array}$ & 21 & 42.0 & 19 & 38.0 & 8 & 16.0 & 2 & 4.0 & 1.82 & 0.850 \\
\hline 5. & $\begin{array}{l}\text { Avoidance of the crowd and } \\
\text { loud noise. }\end{array}$ & 17 & 34.0 & 21 & 42.0 & 10 & 20.0 & 2 & 4.0 & 1.94 & 0.843 \\
\hline 6. & $\begin{array}{l}\text { Denials of thought or feelings } \\
\text { associated with the sad event } \\
\text { and feeling moody. }\end{array}$ & 11 & 22.0 & 25 & 50.0 & 11 & 22.0 & 3 & 6.0 & 2.12 & 0.824 \\
\hline 7. & $\begin{array}{l}\text { Feeling jumpy, easily startled } \\
\text { and fearful. }\end{array}$ & 13 & 26.0 & 20 & 40.0 & 11 & 22.0 & 6 & 12.0 & 2.20 & 0.969 \\
\hline 8. & $\begin{array}{l}\text { Feeling of being on guard, } \\
\text { anxious and feeling of } \\
\text { danger. }\end{array}$ & 13 & 26.0 & 25 & 50.0 & 6 & 12.0 & 6 & 12.0 & 2.10 & 0.931 \\
\hline
\end{tabular}

Objective Three: Determine the nurse-led health education intervention package's effect on the IDPs' most common PTS symptoms.

Table 3 showed the scored means and grand means of PTS symptoms before and after intervention with nurse-led health education. Before the intervention, the grand mean scored through PTS8 was 2.3 , which got reduced to 1.7 two weeks after intervention. This implies that the intervention reduced the PTS symptoms.

Table 3: Effect of intervention on PTS symptoms among IDPs ( $=50)$ (PTS-8)

\begin{tabular}{|c|c|c|c|c|}
\hline & Symptoms & Pre-test & Post-test & \\
\hline SN & Items & M \pm SD. & M \pm SD & 2weeks \\
\hline 1. & $\begin{array}{l}\text { Recurrent thoughts or memories of the event(s) result in } \\
\text { weakness, loss of appetite and sadness. }\end{array}$ & $2.9 \pm 0.8$ & $2.2 \pm 0.7$ & 0.76 \\
\hline 2. & $\begin{array}{l}\text { Feeling as though the event is happening again, } \\
\text { culminating in fear. }\end{array}$ & $2.2 \pm 0.8$ & $2.0 \pm 0.5$ & 0.20 \\
\hline 3. & $\begin{array}{l}\text { Recurrent nightmares/dreams about the event(s) } \\
\text { making me afraid of the night or the sleep. }\end{array}$ & $2.3 \pm 0.9$ & $1.8 \pm 0.8$ & 0.48 \\
\hline 4. & $\begin{array}{l}\text { When reminded of the events, sudden emotional or } \\
\text { physical reactions, e.g. sweating, loss of appetite, } \\
\text { headache, and running stomach. }\end{array}$ & $1.8 \pm 0.9$ & $1.6 \pm 0.7$ & 0.26 \\
\hline 5. & Avoidance of the crowd and loud noise. & $1.9 \pm 0.8$ & $1.7 \pm 0.6$ & 0.26 \\
\hline 6. & Denial of thought or feelings associated with the sad & $2.1 \pm 0.8$ & $1.8 \pm 0.7$ & 0.28 \\
\hline
\end{tabular}


event and feeling moody.

7. Feeling jumpy, easily startled and fearful.

$2.2 \pm 1.0$

$2.1 \pm 0.9$

$2.3 \pm 1.7$

Grand mean

PTS symptom scores among the study population before and after the intervention

Null hypothesis: There is no statistically significant

difference in PTS symptoms scores among the population studied before and after the intervention with nurse-led health education.

Table 4: T-test analysis of IDPs PTS symptoms ( $\mathrm{N}=50)$

\begin{tabular}{|c|c|c|c|c|c|}
\hline & Symptoms & Pre-test & Post-test & $\mathbf{T}$ & p-value \\
\hline $\mathbf{S} / \mathbf{N}$ & Item & M \pm SD & $\mathrm{M} \pm \mathrm{SD}$ & & \\
\hline 1. & $\begin{array}{l}\text { Recurrent thoughts or memories of the event(s) } \\
\text { result in weakness, loss of appetite and sadness. }\end{array}$ & $2.92 \pm 0.78$ & $2.16 \pm 0.65$ & 5.293 & $<.001$ \\
\hline 2. & $\begin{array}{l}\text { Feeling as though the event is happening again, } \\
\text { culminating in fear. }\end{array}$ & $2.16 \pm 0.79$ & $1.96 \pm 0.53$ & 1.487 & 140 \\
\hline 3. & $\begin{array}{l}\text { Recurrent nightmares/dreams about the event(s) } \\
\text { making me afraid of the night or the sleep. }\end{array}$ & $2.26 \pm 0.85$ & $1.78 \pm 0.76$ & 2.977 & .004 \\
\hline 4. & $\begin{array}{l}\text { When reminded of the events, sudden emotional or } \\
\text { physical reactions, e.g. sweating, loss of appetite, } \\
\text { headache, and running stomach. }\end{array}$ & $1.82 \pm 0.85$ & $1.56 \pm 0.67$ & 1.699 & .093 \\
\hline 5. & Avoidance of the crowd and loud noise. & $1.94 \pm 0.84$ & $1.68 \pm 0.55$ & 142 & .070 \\
\hline 6. & $\begin{array}{l}\text { Denials of thought or feelings associated with the } \\
\text { sad event and feeling moody. }\end{array}$ & $2.12 \pm 0.82$ & $1.84 \pm 0.71$ & 1.825 & .071 \\
\hline 7. & Feeling jumpy, easily startled and fearful. & $2.20 \pm 0.97$ & $1.80 \pm 0.70$ & 2.365 & .02 \\
\hline \multirow[t]{2}{*}{8.} & $\begin{array}{l}\text { Feeling of being on guard, anxious and feeling of } \\
\text { danger. }\end{array}$ & $2.10 \pm 0.93$ & $1.84 \pm 0.68$ & 1.596 & .114 \\
\hline & Overall & $2.3 \pm 1.71$ & $1.7 \pm 0.65$ & 2.37 & 020 \\
\hline
\end{tabular}

The comparison between pre and post-test scores of PTS symptoms generally showed that the post-test scores were lower than the pre-test scores. The differences were however significantly observed in these symptoms: recurrent thoughts or memories of the event(s) which results in weakness, loss of appetite and sadness $(\mathrm{p}=0.001)$, frequent nightmares/dreams about the event(s) making IDPs afraid of the night or sleep disturbance $(p=0.004)$ and feeling jumpy, easily startled and fearful $1(\mathrm{p}=0.020)$. The result also showed a significant difference in overall PTS symptoms score before and after intervention with nurse-led health education $(\mathrm{p}=0.020)$, all these at $\mathrm{P}<0.05$ (See Table 4)

\section{DISCUSSION}

Nurse-led health education has reduced the severity of PTS symptoms among the IDPs in camps in Jos, Plateau state. This finding corroborates with the outcome of the work of Richard Shaw, Nick, Lilo, Booil, William, Stevenson \& Horwits (2014) who evaluated the effect of an intervention programme with health education content aiming at the reduction of Post-traumatic stress symptoms among 105 traumatised mothers of preterm infants which significantly resulted in PTS symptom reduction.

The intervention study on effect of health education program among 100 female nursing students at Benha University, Egypt by Eman, Ramadan \& Hanem, (2015) utilizing quasi experimental design and a convenient sample evaluated the effect of health education program on academic stress in the students second and third years and concluded that the program had positive effect in reducing stress symptoms in the study group after the program. In Washington, Dworkin and Schumacher (2016) conducted early intervention study on victims of assault to prevent the development of PTS and concluded that interventions that are perceived positively were associated with lower PTS symptoms. They suggested further, that best practices interventions be carried out, rather than sigmply encouraging survivals to seek help. Other authors have also attested to the efficacy of health education interventional programs which are problem focussed as being good enough for PTS symptoms reduction, (Falex, 2012).

In October 2014, the coordinator of Outreach, Screening and Intervention for Trauma (OSITA) which is an innovative program that aims at 


\section{SJIF Impact Factor: 7.001| ISI I.F.Value:1.241| Journal DOI: 10.36713/epra2016 ISSN: 2455-7838(Online) EPRA International Journal of Research and Development (IJRD)}

improving the mental health and socio-economic condition primarily for vulnerable Internally Displaced Women (IDW) reported the outcome of their studies that, internally displaced women had received screening and psych-education; and those with high stress scores experienced less stress and improvement afterwards ( Gomez, 2014).

In conclusion, we submit that there was evidence of a reduction of PTS symptoms at postintervention. Notably, Nurse-led Health Education resulted in a significant decrease in recurrent thoughts or memories of the events, frequent nightmares/dreams, feeling jumpy, easily startled and fearful as the hypothesis generated and tested indicated in the context of this study, corroborating with similar studies cited in the report (Shaw,et al, 2014; Ramadan, 2015 ). To our knowledge, this is the first study investigating the effect of Nurse-led Health Education on Post Traumatic Stress Symptoms among Internally Displaced Persons, in Jos, Northern Nigeria.

The weakness of this study, may be thought of, and in terms of its setting and limited number of the IDPs studied ( 5o IDPs), thus probably affecting its external validity of results generalization, globally.

We suggest that similar studies of wider scope prospectively be carried out to ascertain sustained effect of nurse led health education on IDPs.

\section{REFERENCES}

1. Adamu, A., \& Rasheed, Z. H. J. G. J. o. H.-S. S. P. S. (2016). Effects of insecurity on the internally displaced persons (IDPs) in northern Nigeria: prognosis and diagnosis. 16(1), 10-21.

2. Bisson, J. I., van Gelderen, M., Roberts, N. P., \& Lewis, C. J. E. J. o. P. (2020). Nonpharmacological and non-psychological approaches to the treatment of PTSD: results of a systematic review and meta-analyses. 11(1), 1795361.

3. Brooks, S. K., Rubin, G. J., \& Greenberg, N. J. B. m. b. (2019). Traumatic stress within disasterexposed occupations: overview of the literature and suggestions for the management of traumatic stress in the workplace.

4. de Moraes Costa, G., Zanatta, F. B., Ziegelmann, P. K., Barros, A. J. S., \& Mello, C. F. J. J. o. P. $R$. (2020). Pharmacological treatments for adults with post-traumatic stress disorder: A network meta-analysis of comparative efficacy and acceptability.

5. Ede, V. I. (2019). Addressing Conflict-induced Internal Displacement in Nigeria: The Religious Option.

6. Ellis, B. H., Winer, J. P., Murray, K., \& Barrett, C. (2019). Understanding the mental health of refugees: Trauma, stress, and the cultural context. In The Massachusetts General Hospital textbook on diversity and cultural sensitivity in mental health (pp. 253-273). Springer.

7. Fingerle, M., \& Wink, R. (2020). Forced Migration and Resilience: Introduction. In Forced Migration and Resilience (pp. 1-9). Springer.

8. Haagen, J. F., ter Heide, F. J. J., Mooren, T. M., Knipscheer, J. W., \& Kleber, R. J. J. B. J. o. C. P. (2017). Predicting post-traumatic stress disorder treatment response in refugees: Multilevel analysis. 56(1), 69-83.

9. Hansen, M., Andersen, T. E., Armour, C., Elklit, A., Palic, S., Mackrill, T. J. C. p., CP, e. i. m. h., \& EMH. (2010). PTSD-8: a short PTSD inventory. 6, 101. $n$

10. Hu, Q.-M., Zhao, L., Li, H., \& Huang, R. J. I. T. (2019). Integrated design of emergency shelter and medical networks considering diurnal population shifts in urban areas. 51(6), 614-637.

11. Internal Displacement Monitoring Centre. (2020). Global Report on Internal Displacement. https://www.internal-displacement.org/globalreport/grid2020/

12. Klaus, W., \& Pachocka, M. J. I. M. (2019). Examining the global north migration policies: A "push out-push back" Approach to forced migration. 57(5), 280-293.

13. Lewis, S. J., Arseneault, L., Caspi, A., Fisher, $H$. L., Matthews, T., Moffitt, T. E., Odgers, C. L., Stahl, D., Teng, J. Y., \& Danese, A. J. T. L. P. (2019). The epidemiology of trauma and posttraumatic stress disorder in a representative cohort of young people in England and Wales. 6(3), 247-256.

14. Marshall, J., Wiltshire, J., Delva, J., Bello, T., \& Masys, A. J. (2020). Natural and Manmade Disasters: Vulnerable Populations. In Global Health Security (pp. 143-161). Springer.

15. Mavranezouli, I., Megnin-Viggars, O., Daly, C., Dias, S., Welton, N. J., Stockton, S., Bhutani, G., Grey, N., Leach, J., \& Greenberg, N. (2020). Psychological treatments for post-traumatic stress disorder in adults: a network metaanalysis. J Psychological Medicine, 50(4), 542555.

16. Michael Ihuoma, O. J. E. (2019). The Economics and Dynamics of Internal Displacement in Nigeria. 55.

17. Mooney, E. (2005). The concept of internal displacement and the case for internally displaced persons as a category of concern. Refug Surv Q, 24(3), 9-26. https://doi.org/10.1093/rsq/hdi049

18. Morina, N., Akhtar, A., Barth, J., \& Schnyder, U. (2018). Psychiatric disorders in refugees and internally displaced persons after forced displacement: A systematic review. FRONT PSYCHIATRY, 9, 433-433. https://doi.org/10.3389/fpsyt.2018.00433

19. Muir, J. A., Cope, M. R., Angeningsih, L. R., Jackson, J. E., Brown, R. B. J. I. j. o. e. r., \& health, p. (2019). Migration and mental health in 


\section{EPRA International Journal of Research and Development (IJRD)

the aftermath of disaster: evidence from Mt. Merapi, Indonesia. 16(15), 2726.

20. Olanrewaju, F. O., George, T., Ayodele, O. T., \& Olanrewaju, A. O. (2020). Media Advocacy: A Strategy for Addressing Health Concerns in Internally Displaced Persons (IDPs) Camps in Nigeria. In Handbook of Research on the Global Impact of Media on Migration Issues (pp. 253271). IGI Global.

21. Olanrewaju, F. O., Olanrewaju, A., Omotoso, F., Alabi, J. O., Amoo, E., Loromeke, E., \& Ajayi, L. A. J. S. O. (2019). Insurgency and the Invisible Displaced Population in Nigeria: A Situational Analysis. 9(2), 2158244019846207.

22. Owoaje, E., Uchendu, O., Ajayi, T., \& Cadmus, E. (2016). A review of the health problems of the internally displaced persons in Africa. Niger Postgrad Med J, 23(4), 161-171. https://doi.org/10.4103/1117-1936.196242

23. Polit, D., Beck, C., Hungler, B. J. A., \& Utilization. (2006). Essentials of Nursing Research: Methods.

24. Ramadan, E., Ahmed, H. J. I. J. o. N., \& Science, H. (2015). The effect of health educational program on depression, anxiety and stress among female nursing students at Benha University. 4(3), 49-56.

25. Roberts, N. P., Kitchiner, N. J., Kenardy, J., Robertson, L., Lewis, C., \& Bisson, J. I. J. C. D. o. S. R. (2019). Multiple session early psychological interventions for the prevention of post-traumatic stress disorder. (8).

26. Satkoske, V. B., Kappel, D. A., \& DeVita, M. A. J. C. c. c. (2019). Disaster ethics: shifting priorities in an unstable and dangerous environment. 35(4), 717-725.

27. Sepahvand, H., Hashtjini, M. M., Salesi, M., Sahraei, H., Jahromi, G. P. J. I. j. o. p., \& sciences, $b$. (2019). Prevalence of post-traumatic stress disorder (PTSD) in Iranian population following disasters and wars: a systematic review and meta-analysis. 13(1).

28. Shaw, R. J., St John, N., Lilo, E., Jo, B., Benitz, W., Stevenson, D. K., \& Horwitz, S. M. J. P. (2014). Prevention of traumatic stress in mothers of preterms: 6-month outcomes. 134(2), e481e488.

29. Siriwardhana, C., Wickramage, K. J. C. H. o. P., Health, \& Medicine. (2019). Migration, Displacement and Health. 164.

30. Spialek, M. L., Houston, J. B., \& Worley, K. C. J. J. o. h. c. (2019). Disaster communication, posttraumatic stress, and posttraumatic growth following Hurricane Matthew. 24(1), 65-74.

31. Tagurum, Y. O., Chirdan, O. O., Obindo, T., Bello, D. A., Afolaranmi, T. O., Hassan, Z. I., \& Yilgwan, C. (2014). Prevalence of violence and symptoms of post-traumatic stress disorder among victims of ethno-religious conflict in Jos, Nigeria.

32. Uzobo, E., Akhuetie, R. E. J. T. N. J. o. S., \& Anthropology. (2018). Food Security and Health
Challenges among Internally Displaced Persons in Nigeria. 16(1), 47-71.

33. Van Daele, T., Hermans, D., Van Audenhove, C., \& Van den Bergh, O. (2012). Stress reduction through psychoeducation: a meta-analytic review. Health Educ. Behav, 39(4), 474-485.

34. Zhang, S., \& Zhang, D. D. J. S. C. E. S. (2019). Population-influenced spatiotemporal pattern of natural disaster and social crisis in China, ADI1910. 62(7), 1138-1150. 